\title{
PURPOSE OF HUMAN EDUCATION IN THE CONDITIONS OF FORMATION OF INFORMATION SOCIETY
}

\section{Kravtsov Yu. S.}

\section{INTRODUCTION}

The fundamentality of modern humanities education is determined not by the translation of fundamental knowledge, through the loss of a universal and unified context of research, but by the focus on the formation of creativity as a fundamental structure of human being, on the conceptualization of activities that have productive theoretical potential. Modern transformation includes components of modernization, postmodernization, traditional retreat. Such combination of seemingly incompatible processes without category "transformation of society" would have looked eclectic, mechanistic if the transformation would be considered regardless of globalization.

The changes taking place in the modern world, the modern socio-cultural situation, require a modern man's mobility and an adequate response to modern requirements of society, put it before the need to revise traditional goals and landmarks. In the work, the authors show that in the pedagogical sense, this means that the main result of education should not be a system of knowledge, skills and skills by itself, but a set of modern key competences in the intellectual, social, legal, communicative, informational spheres.

\section{Variations virtual forms of social interactions in the information society}

In the beginning, we will analyze theoretical foundations of the information paradigm, to reveal from the philosophical standpoint the ontological and epistemological factors of the emergence of a new historical type of society, in our case - information. According to information ontology, reality is identical to information. Within this paradigm, the human person is reduced to the sum of information contained in it. The concept of information society points to the principle around which this social form is organized - information and knowledge. The information society arises where the management, not of material objects, but of symbols, ideas, images, intelligence, and where most of those who work, are engaged in the 
production, storage and realization of information, especially its higher form - knowledge, becomes the main ${ }^{1}$

In his research, T. Stonier points out that in the modern information society, the role of capital is played by information. Like capital, information can be accumulated, and in this sense national information resources determine the economy and wealth of the country. In this regard, the information economy is the most important part of any country's economy. Economy in a post-industrial society is characterized by the fact that industry is increasingly replaced by a service sector that is oriented to the production and processing of information in terms of employment and a major share in the national product ${ }^{2}$.

In this regard, the problem of model operability is eliminated, but the problem remains with the modeling process itself, because before creating any model - material, cybernetic - the researcher must construct an imaginary model. At this stage, he should take into account the fundamental difference between the natural-scientific and socio-humanitarian models, namely, the difference in order to build models. Conducting experimental research is the primary purpose of model building in the natural sciences, whereas in the socio-humanitarian field of knowledge it is the ability to interpret a complex phenomenon or process.

An educated person finds the support of his or her existence in subjective experience: values, beliefs, knowledge, abilities, etc. It masks changes, controls them, projects them for the future through goal setting. Innovative education focuses primarily on the formation of creative and, at the same time, critical thinking combined with tolerance. It is focused on human growth.

It should be noted that the global information society, market economy and scientific and technological revolution require new human social and individual qualities. In particular, an essential skill in a postmodern society is the ability to give advice on change. The point is that in the information society, information is lacking and wisdom is lacking in how to use it. Society is interested in the fact that every citizen is intellectually independent, that is, does not trust others to think for him and make choices. As M. Lipman rightly points out, we must learn to think for ourselves. No one will teach us this unless it puts us in a research community where it is relatively easy to achieve this goal. M. Lipman notes that critical thinking is

${ }^{1}$ Lotman Iu. M.(1988) Text and audience structury. Riga. Daugavaю p. 21-24.

2 Stounj'er Gh. Information Wealth: Post-Industrial Economics Profil. Novaja tekhnokratycheskaja volna na Zapade. Moscow, AST Publishing House. p. 394. 
in line with the democratic way of education, shaping the mentality not only of generations of countries of consolidated democracy, but also democratizing the mentality of citizens of the newly independent states ${ }^{3}$.

The urgency of critical thinking grows during periods of social change that impede the success of actions, requiring constant adaptation to new political, economic situations and the like, effective solutions to problems that cannot be foreseen in advance. In particular, the information society has significantly increased the choice and complexity of the problems that need to be addressed. Transformation-driven informatization is quite significant, as it contains "modeling of information processes, restructuring of organizational structures, documents, legal norms, as well as appropriate training and retraining of personnel. It is a programmed restructuring of the social information environment, creation of fundamentally new automated methods and conditions for the production, replenishment, processing, transfer and use of knowledge, an effective method of intellectual activity"4.

The relevance of communication issues today is also due to the fact that the modern high school has been replenished with new educational areas, which can rightly be called interdisciplinary (public relations, social work, and the like). The specialties of the traditional philological cycle have also included an applied aspect (linguistics and intercultural communication, linguistics and information science, and the like). Many Western universities also have offices and faculties of communication. Research programs related to the study of communication in industrial, political, educational, medical and other social fields are expanding. All these areas are related to the provision of information flows in contemporary society, both on an interpersonal and global level, both through traditional (oral, typing) and modern (television, Internet) means.

Again, the theoretical core around which the disciplines of this profile are grouped is communication theory. Communication theory in Englishlanguage science in the 90s developed, first of all, around the problems of mass media, as well as new communicative realities of marketing and management, which emerged as a result of a symbiosis of media and market technologies (communication management, advertising communication, corporate identity, marketing communications, etc.) The specialist communicator of the field must have a certain knowledge of the basics of the

3 Lipman M. (2005) Critical is misunderstanding: what can we do? In Postmethodika. №2 (60), ( pp. 33-41). Moscow : Izd-vo MGU. P. 76.

${ }^{4}$ Stounj'er Gh. Information Wealth: Post-Industrial Economics Profil. Novaja tekhnokratycheskaja volna na Zapade. Moscow, AST Publishing House. p. 395. 
communication process and skills in conducting information and communication activities in different environments (economy, production a, management, ecology, culture, health care, agricultural production, mass physical culture, recreation and sports, cultural and tourist exchanges, in the fuel and energy complex, small business, political, social, scientific, financial and banking spheres). A representative of the new professions (press secretary, advertising and communications manager, expert, consultant, referent in government, commercial and public institutions and organizations, structures) should be familiar with the basic theories and concepts related to the field of information, communication and the formation of public thoughts, have information and communication skills, advertisinent.

According to information ontology, reality is identical to information. Within this paradigm, the human person is reduced to the sum of information contained in it. The concept of information society points to the principle around which this social form is organized - information and knowledge. The information society arises where the management, not of material objects, but of symbols, ideas, images, intelligence, and where most of those who work, are engaged in the production, storage and realization of information, especially its higher form - knowledge, becomes the main. In his research, T. Stonier points out that in the modern information society, the role of capital is played by information. Like capital, information can be accumulated, and in this sense national information resources determine the economy and wealth of the country. In this regard, the information economy is the most important part of any country's economy. Economy in a postindustrial society is characterized by the fact that industry is increasingly replaced by a service sector that is oriented to the production and processing of information in terms of employment and a major share in the national product $^{5}$. D. Bell points out that the role of agriculture and industry is changing as a result of the growing importance and expansion of the information industry. The emergence of a post-industrial society contributes to a revolution in the organization, functioning, processing of knowledge. The computer plays a decisive role in the development of the information society. Bell calls this revolution "telecommunication" and identifies three of its most important aspects: the transition from an industrial to a service society, the decisive importance of codifying theoretical knowledge for the implementation of technological innovation, the transformation of

5 Stounj'er Gh. Information Wealth: Post-Industrial Economics Profil. Novaja tekhnokratycheskaja volna na Zapade. Moscow, AST Publishing House. p. 394. 
"intellectual technology" into a key tool in decision theory, system analysis . In this case, the nature of the information society is determined by internal communication within the society, communication that is deployed by means of telecommunication technologies ${ }^{6}$.

Thus, we can speak of language as a phenomenon that exists for the accumulation, transmission and creation of new information, as a phenomenon that forms the primary information environment of man. With this approach, the language researcher inevitably faces the problem of determining the kinds of linguistic information and the means by which different kinds of information can be transmitted, because even at first glance it becomes clear - this unusually complex, hierarchically organized communication system consisting of multiple levels, allows you to operate information blocks of varying degrees of complexity. In this case, we can assume that different information functions are assigned to units of different levels.

F. de Saussure characterized linguistic reality as the unity of opposing parties: sign and meaning, language and speech, social and individual. The dual nature of language, after all, is determined by its role as a mediator between activity and cognition. From the activity, it borrows from the transformed form of object transformation: each special method in action is a private model of an individual object. From the consciousness side, language finds the ability to explicate fixed information in signs. "Operationality" and "objectivity" of the language are interdependent, "verbal signs are not just fixed", dress "thoughts, they act as tools for the actual process of thinking. These functions of "lock" and "operator" are common to signs of both natural and artificial languages"?

The problem of model operability is therefore eliminated, but the problem remains with the modeling process itself, because before creating any model - material, cybernetic - the researcher must construct an imaginary model. At this stage, he should take into account the fundamental difference between the natural-scientific and socio-humanitarian models, namely, the difference in order to build models. Conducting experimental research is the primary purpose of model building in the natural sciences, whereas in the socio-humanitarian field of knowledge it is the ability to interpret a complex phenomenon or process.

6 Bell D. (1986) Social framework of the Information Society In New Technocratic Wave in the West. p. 334.

7 Butenko E.V. (2004) Evolution of the theory of the information society: Extended abstract of kandsdate's thesis. Tomsk, TGhU. p. 10. 
The relevance of communication issues today is also due to the fact that the modern high school has been replenished with new educational areas, which can rightly be called interdisciplinary (public relations, social work, and the like). The specialties of the traditional philological cycle have also included an applied aspect (linguistics and intercultural communication, linguistics and information science, and the like). Many Western universities also have offices and faculties of communication. Research programs related to the study of communication in industrial, political, educational, medical and other social fields are expanding. All these areas are related to the provision of information flows in contemporary society, both on an interpersonal and global level, both through traditional (oral, typing) and modern (television, Internet) means.

Again, the theoretical core around which the disciplines of this profile are grouped is communication theory. Communication theory in Englishlanguage science in the 90s developed, first of all, around the problems of mass media, as well as new communicative realities of marketing and management, which emerged as a result of a symbiosis of media and market technologies (communication management, advertising communication, corporate identity, marketing communications, etc.) The specialist communicator of the field must have a certain knowledge of the basics of the communication process and skills in conducting information and communication activities in different environments (economy, production a, management, ecology, culture, health care, agricultural production, mass physical culture, recreation and sports, cultural and tourist exchanges, in the fuel and energy complex, small business, political, social, scientific, financial and banking spheres). Representatives of new professions (press secretary, advertising and communications manager, expert, consultant, referent in government, commercial and public institutions and organizations, structures) should be familiar with the basic theories and concepts related to the field of information, communication and public thoughts, have information and communication skill.

\section{Changes in the settings of humanitarian edication in modern society}

The processes of informatization of modern education should not be understood solely as the formation of technical means that enhance the external effectiveness of the educational process; they represent those sociocultural changes that change the tasks and image of humanitarian education in the modern world. The general tendency to change the content of education is connected with the transition from the consideration of the 
professional as the purpose of training to the consideration of a comprehensive and harmoniously developed personality as the purpose of education. One of the urgent tasks of philosophy at the present stage is to create ideas and concepts related to the problem of unity, integrity, globalization. The formulations of unity theorists invariably include among the initial and fundamental values of modern European unification the understanding of human rights and freedoms that goes back to the formulations of modern-day philosophers and to the socio-political documents of this era. This undoubtedly proves the effect of philosophical ideas and researches that precede the real process of human history.The debate over what knowledge is more important to society: technical or humanitarian, known as the problem of "physicists and lyricists", has recently been resolved in favor of the humanities. Compared to a computer, we can say that philosophy plays the role of software in human society, that is, software, and the technical sciences - hardware, or hard-ware society. What is most expensive and important in a computer is well known: without software, the computer and all the additional devices turn into a pile of iron.So far, there have been two main trends in the field of predicting the future: utopia and dystopia. In the XIX and XX centuries was set a kind of record for the "production" of social utopias. Experience shows that they do not bring benefit to humanity and do not have a "positive" influence on the development of historical events. This is due to the fact that utopias are an escape from reality, they are trying to imagine the future in a cloudless light. One can recall such authors as Utopia, such as T. Campanela, T. More, and S. Fourier.

Anti-utopias emphasize the tendencies of human development, but they do not contain the goals that society should strive for. Authors of dystopias (D. Swift, R. Chesterton, EI Zamyatin, D. Orwell) see the future in a gloomy light and usually do not find ways to overcome negative trends. Among modern methods of social forecasting is possible highlight the following: 1) extrapolation; 2) historical analogies; 3) future scenarios; 4) expert assessments; 5) Synergetics and computer modeling. Each of these methods of predicting the future has its merits and disadvantages. For example, extrapolation accuracy decreases with the removal of predicted events into the future. This remark is especially true of periods of societal chaotic stages of development. Historical analogies also have limitations: the future cannot in its main features repeat the past, otherwise this future is a simple continuation of the past. Each historical era has its own individual characteristics and circumstances that must be taken into account when making a decision. However, according to synergists, the results of the 
selection of social structures in the process of their development influence the selection factors themselves. Therefore, unlike G. Hegel, synergists believe that participants in the historical process draw lessons from history. In today's futuristic literature, the most common predictions are based on future scenarios. Among the authors of studies of this type can be called E. Tofler, M.M. MS. Huntington, F. Fukuyama.

Trying to predict the future, E. Toffler seeks to distance himself from both Utopians and authors of dystopias. For his prediction, he even introduced the special name "praktopiya": practical utopia. Such a name corresponds to the description of a more practical and human-friendly world than the one in which we live now. The Third Wave Society (as E. Toffler calls the information society) "is not just a nightmare continuation of industrialism $\langle\ldots\rangle$ not the best or the worst of the possible worlds $\langle\ldots\rangle$ it is a practice that encourages individual development, welcomes racial, religious and cultural diversity. It is a civilization, largely organized around the house but not frozen, and one that gives rise to a new, capable of providing stability to those who need it",

Huntington sees the causes of the coming conflicts in the civilizational (cultural) differences of peoples. In his book "The Clash of Civilizations" $\mathrm{S}$. Huntington analyzes the world order that has emerged since the end of the Cold War and tries to predict the global trends in its development. Major conflicts of the future will occur between peoples of different cultural identities. S. Huntington even introduces the notion of "Line of fault between civilizations", clearly imitating the geological terminology of plate tectonics: it is precisely within the limits of tectonic faults that the most significant geological events occur. The analogy is reinforced by the fact that "civilizations do not mix with each other and change only on a historical scale of time" - this was the discovery made by M. Danilevsky. He also introduced into science the concept of different civilizations coexisting on the globe, the formation of which is associated with the features of the dominant landscapes ${ }^{9}$ The achievements of post-classical science in such areas as synergetics and chaotic dynamics allow us to take a fresh look at the process of social development as a natural alternation of order and chaos. The traditional dialectical concept, developed in the works of G. Hegel and $\mathrm{K}$. Marx, is characterized by the idea of development as a process of

${ }^{8}$ Stounj'er Gh. Information Wealth: Post-Industrial Economics Profil. Novaja tekhnokratycheskaja volna na Zapade. Moscow, AST Publishing House. p. 569-570.

${ }^{9}$ Pereslegin S.B. (2005) The tutorial of the game on the world chessboard. Moscow : AST. p. 88. 
transition from one order to another. The chaotic stage of development was either not taken into account or regarded as an insignificant moment of development.

Hierarchy means the sequential unification of elementary dissipative structures into more complex dissipative structures, and hierarchy means the decomposition of complex dissipative structures into simpler ones. Moments of union or breakup in chaotic dynamics are called bifurcations of the system. It is in the process of bifurcation that the choice of a set of potentially possible social structures of some one structure is made. Social selection is the driving force behind the self-organization of the system. Another important discovery of synergetics is that the selection results influence the selection factors: thesaurus, detector and selector. This means that there is feedback between the results and the selection factors.

1. An example of applying a synergistic approach and computer modeling to predict social development can be found in D.S. Chernavsky's book Synergetics and Information. It examines a model of a self-evolving system that describes the process of interacting with a sufficiently large number of competing elements. This model can be used in many different fields: biology, linguistics, sociology and history ${ }^{10}$.

The further course of the historical development of post-industrial society cannot be predicted unequivocally. This is due to the bifurcation nature of the coming changes. Therefore, the predictions of the postbifurcation state are multivariate. There are several basic scenarios for the development of society: 1 . Attempts to preserve the current situation. TNC control over the world. Maintaining the technological structure of developed countries; 2. Transition to the world totalitarian system. Gold billion strategy. Slow development of third world countries; 3. The New Middle Ages. Choosing the second option in the alternative "either to reduce the population by 10 times or to reduce the consumption of resources by 10 times"; Demographic explosion in third world countries, accompanied by technological stagnation and inhibition. The transition to a totalitarian system. The split of the world community beyond civilizational faults, according to the theory of "collision of civilizations" by S. Huntington; 4. Global Environmental Disaster; 5. Transition to the information society, to the noosphere (to some extent it can be assumed that it has already taken place.

${ }^{10}$ Chernavskyj D.S. (2000) The problem of the origin of life in thinking from the point of view of modern physics / Uspekhy fyzycheskykh nauk. T. 170(2). p. 175. 
All of the above options for further development can be considered as possible stable states of society after the chaotic stage of development. Some researchers believe that the stage of chaotic development has already come, and even called this stage of development: "postmodern". The particular characteristics of postmodernism are indeed consistent with the concept of the chaotic stage of social development.

To align human activity with the capabilities of the biosphere will require new behaviors and relationships of people, a new understanding of the nature and place of man in it. The future of all mankind depends to a great extent on how much we will be able to subordinate our individuality to a certain social need, on what ratio the utilitarian and spiritual components of social ideals will be. Negative phenomena in the environment in the interaction of man with nature occur in the case of neglect or spiritual, or utilitarian ideals.

The formation of a creative, initiative person capable of effective activity, as the main purpose of education determines the content of its target settings. The internal logic of the self-motion of the subject of the educational process, which organizes the educational space, is based on the idea of the model of competence of the person. The model of competence of the person as the whole of the educational system assumes: social competence, which consists in mastering the rules and norms of basic social practices; awareness of one's own social and cultural identity in the historical and cultural horizon; intellectual and communicative competence, which is the ability to reflect one's own point of view, to critically check it, to change it, to relate it to other points of view, and to use modern methods, forms and technologies of communication; worldview competence, which implies tolerance of values and norms of other cultures, adoption of values of social and cultural initiative, adoption of ethical regulators that underlie responsible action; professional competence.

This model is based on the idea of the humanitarian dimension of the information society and the priorities of modern humanitarian education. In industrial society, priority was given to pragmatic, technocratic education. The peculiarity of the current situation of becoming an information society is that humanitarian dimension and humanitarian education take priority. Unlike the technocratic view, the humanitarian considers the development of the individual and the creation of conditions for his safe and dignified existence as a goal, not as his means ${ }^{11}$.

11 Butenko E.V. (2004) Evolution of the theory of the information society: Extended abstract of kandsdate's thesis. Tomsk : TGhU. p. 18. 
M.I. Romanenko, highlighting the characteristics of the post-classical philosophical and educational paradigm, draws attention to the fact that the projective component of education based on synergetic methodology comes first. At the same time, through projectivity, education acquires the traits of aesthetic creativity (a whole new paradigm indicator of the "educational society"). These conclusions are important, first of all, as recognition of the conformity of the general existential-value of modern philosophical and educational paradigm, associated with "anthropocentric restructuring of the educational process and humanization of educational practices socio-cultural reorientation in the interpretation of relationships between human and society, surrounded and ontologized these relationships by recognizing their existential meaning for each individual" ${ }^{\prime 2}$.

An educated person must quickly and effectively solve the tasks that determine the level of his personal competence, on which depends the degree of his cultural productivity, his social quality. Therefore, education can be considered to have taken place only when it involves not only the development of knowledge but also the formation of values. Moreover, the level of functional improvement of a specialist depends on the successful combination of functional knowledge and humanitarian training in his professional education.

The traditional concept of humanitarian education is that it has the task of learning the forms and methods of interaction of social agents, social norms, attitudes and goals, and the task of creating the conditions for the person to understand and understand his place in the social system and in the world as a whole. Thus, it aims at forming fundamental foundations that will allow a person to solve world-view tasks, make ethical, legal or ideological choices, navigate the current socio-cultural situation.

The emergence of an information society is linked to changes in humanitarian training tasks. In modern conditions, they can be distorted. The distorted image of humanities education in the information society and its implementation in modern education are linked to two extremes in understanding the function and features of humanitarian education. First, humanitarian education is understood as a way of constructing human existence, as a universal means of solving ideological problems. It is seen as a form of manipulation of human consciousness. In the conditions of the information society, this path is dangerous because it will not allow the formation and implementation of the necessary personal competence, since

12 Romanenko M.I.(2003) Social and paradigm-cognitive determinants ofdevelopment of modern education. Doctors tesis. Dnepr. p. 198. 
it negates the responsibility and autonomy of a person based on his freedom. Second, the secondary and external character of humanitarian education is approved. This approach is based on the idea of a technocratic society, in which the humanities education does not determine the level and quality of technology development, and therefore does not affect the organization and quality of life and does not constitute the main resource of society development. The consequences of this approach are obvious - the global crisis as a result of the destruction of the form of human existence ${ }^{13}$.

Therefore, the fundamentality of modern humanities education is determined not by the translation of fundamental knowledge, through the loss of a universal and unified context of research, but by the focus on the formation of creativity as a fundamental structure of human being, on the conceptualization of activities that have productive theoretical potentials.

The dynamism of the society, the openness and uncertainty of the future create the conditions for the deployment of innovative processes, the development of a project culture, which is oriented to forecasting and building a new, purposeful change in social practices. The concept in the project culture system begins to fulfill the function of forming a new type of practice. Project thinking, as opposed to a research approach, is always a practice-oriented mindset aimed not only at widening the theoretical horizon but also at building a new type of practice. Creating models for constructing a social future in terms of value-semantic variability relies on understanding humanity as a new quality of fundamental science and education.

The organization of the space of activity and communication in the conditions of becoming an information society is based on its systematic understanding, which is carried out by conceptualization. It performs both the function of imagination and the function of activity management. Its instrumental character is emphasized by the interaction of theoretical and practical.

Humanitarian education is shaped by the ability to conceptualize as the basis of modern social practices through the development of value-meaning orientations of activity, the development of ways of its reflection, the formation and development of the system of differences and communication agents of social and cultural practices, through the formation of the ability of project concretization of the conceptualization. The focus on problematizing existing approaches, theories, and activities to enhance their effectiveness in fulfilling the humanitarian goals and objectives of the information society

${ }^{13}$ Belova L. Gh. (2010) What do we know about the information society. Vestnyk MGhU. Ser. 14, Эkonomyka. 4. p. 79. 
distinguishes the design of the humanities education in the information society from the traditional ideas about it, according to which it is limited to the task of transmitting knowledge, society and their life forms

In these circumstances, humanitarian education has the task of discovering and implementing the fundamental structures of human existence, which serve as a condition for creative development and effective application of modern humanitarian knowledge. This task corresponds to the post-neoclassical image of science. It is about the unity of the human person in his communication, understanding, imagination, self-creation and worldmastery, the parameters and forms of which modern humanities education can set. The implementation of this task affects the structure, form, content and methodology of humanitarian education.

It should be noted that there are favorable conditions for the implementation of the humanitarian approach to education in the current educational situation. In today's dynamic society, value and semantic variability are needed and the impact of the advancing development of education on the formation of social innovations is recognized. The dynamically changing conceptual field of modern educational practices, the aspirations and attempts of humanization and humanization of education, taking into account the realities of the information society, are favorable factors for the creation and implementation of the concept of development of humanitarian education, which allows different ways of realization.

The necessary step-by-step changes in the structure, content, technology of humanitarian education are dictated and reflect the transformation of the forms and content of the humanities, humanitarian knowledge and knowledge.

A change in the study's landmarks, a departure from the position of a neutral observer and a universal theoretical horizon in humanitarian research lead to a change in its character. The poly-paradigm of humanitarian knowledge determines the pluralistic, open-ended nature of humanitarian inquiry. The center-hierarchical system is replaced by the space of additional systems, the communication of which forms visual areas and the content of research $^{14}$.

Humanitarian cognition is interdisciplinary, the principle of additionality determines the way in which different disciplines interact. The complex nature determines the effectiveness, theoretical productivity and direction of research. The humanities are developed by the emergence of specializations,

14 Butenko, E.V. (2004) Evolution of the theory of the information society: Extended abstract of kandsdate's thesis. Tomsk : TGhU. p. 14. 
the emergence of related fields of study, which are considered in the context of updating the fundamental structures of human existence. The information processes and structures that provide them change not only the technical, instrumental aspects of research, forms and ways of working with humanitarian material, but also themselves become an essential and necessary subject of research and a factor that determines the notion of humanitarian research and its thematic sphere. They orient contemporary humanitarian research to a sociocultural context that defines the pragmatic and projective nature of humanitarian knowledge.

Updating and expanding environmental topics, implementation of environmental projects is a necessary form of realization of the outlook set up within the framework of modern humanitarian research. The requirements of environmental safety and the results of the study of the ecological level of human existence define as a priority regulatory rather than consumer attitude to nature as a condition of harmonious human existence and sustainable development. As part of the formation of the outlook setting, a synthesis of humanitarian and natural-scientific knowledge as necessary and additional forms and levels of development of the world is carried out.

The changes taking place and the current level of humanitarian research determine the vector of transformation of humanitarian education in the conditions of formation of information society.

The development of humanitarian education, taking into account the objectives and trends of the development of education and humanitarian knowledge, involves the implementation of the principle of openness of humanitarian education to social practices and the principle of its accessibility without limiting age and geographical location. Humanitarian education in the information society involves the formation of an intention for continuing education and the ability to educate itself by creating structures, forms and technologies that provide them. A special role in the solution of this problem belongs to distance education.

The development of a liberal arts education in the information society is aimed at implementing a multidisciplinary approach, that is, assuming a multilevel and comprehensive analysis of the humanitarian phenomenon and its holistic comprehension in terms of alternative interpretative strategies that represent diverse cultural positions. This approach should ensure the effectiveness of the development and application of humanitarian knowledge and form a conscious responsible choice in terms of diversity of cultural values, cultural self-determination. At the level of organization of 
educational practice, the variability of the content of humanitarian education is assumed.

The development of a liberal arts education in an information society environment is directed towards its integration with science education. It provides the rigor and accuracy of the methodological and technical aspects of the humanities education, which largely determines its objectivity and effectiveness. It is carried out on the basis of a synthesis of theoretical and practical activities, humanitarian education is pragmatic. A form of such synthesis within humanities education is project education. The method of projects allows to reveal practically oriented character of the humanities education and to offer a pragmatic criterion of the humanities education. In this way, it is possible to involve in the educational process the social environment, which is a prerequisite for the formation of social and regional competence, the capacity for effective social action.

\section{CONCLUSIONS}

Summary Increasing the effectiveness of education through the achievement of the clarity and accuracy of humanitarian cognition, wherever it is possible to process a large amount of information, all this is ensured by the use of mathematical apparatus and information technology tools. However, computer science is not only of secondary importance, but also becomes a humanitarian discipline. A special place in the field of humanitarian education is given to language, rhetorical preparation, aimed at assimilation, presentation and creation of new cultural models, dialogue and polylogue of cultures. The attempt to construct a model of social processes, which claims to be "objectivity" in the sense of not burdening any point of view, on the path of direct appeal to social phenomena, as history shows, inevitably ends with ideology. On the other hand, any social phenomenon is usually considered in any aspect, is understood within a limited set of prerequisites, and any further interpretation is carried out by private rules ("horizon of knowledge"). This means that there is no state of affairs in social life that is not affected by interpretation; moreover, the social phenomenon is never fully disclosed.

\section{SUMMARY}

The universal value horizon, perceptions of universal values are not reflected in contemporary cultural practices. On the one hand, culture becomes value-oriented, its phenomena become the object of appreciation, values and structure and organization, on the other hand, value pluralism, 
polyparadigmality, relativism and irreducibility of values are apparent to one another.

\section{REFERENCES}

1. Bell D. (1986) Social framework of the Information Society. In New Technocratic Wave in the West. (pp. 330-342) Moscow : Mysl [in Russian].

2. Belova L. Gh. (2010) What do we know about the information society. Vestnyk MGhU. Ser. 14, Эkonomyka. 4. Pp. 109-119 [in Russian].

3. Butenko, E.V. (2004) Evolution of the theory of the information society: Extended abstract of kandsdate's thesis. Tomsk : TGhU [in Russian].

4. Lipman, M. (2005) Critical is misunderstanding: what can we do? In Postmethodika. №2 (60), ( p.p. 33-41). Moscow : Izd-vo MGU [in Russian].

5. Lotman Iu. M. (1988) Text and audience structury. Riga. Daugava [in Latvian].

6. Pereslegin, S.B. (2005) The tutorial of the game on the world chessboard. Moscow : AST [in Russian].

7. Romanenko M.I. (2003) Social and paradigm-cognitive determinants of development of modern education. Doctors tesis. Dnepr. [in Ukrainian].

8. Sosyur F.(1977) Proceedings of linguistics. Moscow : Progress [in Russian].

9. Stounj'er Gh. Information Wealth: Post-Industrial Economics Profil. Novaja tekhnokratycheskaja volna na Zapade. Moscow, AST Publishing House, [in Russian].

10. Chernavskyj, D.S.(2000) The problem of the origin of life in thinking from the point of view of modern physics / Uspekhy fyzycheskykh nauk. T. 170(2) (157-183) [in Ukrainian].

\section{Information about the autor: Kravtsov Yu. S.,}

Doctor of Philosophical Science, Associate Professor, Professor of the Department of Sociology

Dniprovsk State Technical University

2, Dnipropetrovskaya str., Kamenskoe, Dnipropetrovsk region, Ukraine 